\title{
Can I have More Problems to Practice? Student Usage and Course Success Related to Auto-graded, End-of-chapter Problems in a Material and Energy Balances Course
}

\section{Kayla Chapman,}

Kayla Chapman is currently studying chemical engineering at the University of Toledo and expects to earn a B.S. degree in 2021. She has assisted with multiple areas of research and data analysis regarding zyBooks reading participation and challenge activities. She became interested in performing research after completing a chemical engineering course that used zyBooks.

\section{Prof. Matthew W. Liberatore, The University of Toledo}

Matthew W. Liberatore is a Professor of Chemical Engineering at the University of Toledo. He earned a B.S. degree from the University of Illinois at Chicago and M.S. and Ph.D. degrees from the University of Illinois at Urbana-Champaign, all in chemical engineering. His current research involves the rheology of complex fluids as well as active learning, reverse engineering online videos, and interactive textbooks. His website is: http://www.utoledo.edu/engineering/chemical-engineering/liberatore/ 


\title{
Can I have more problems to practice? Student usage and course success related to auto-graded, end-of-chapter problems in a material and energy balances course
}

\begin{abstract}
Online homework and interactive textbooks provide big data that can help address many questions about student engagement and learning. Auto-graded homework questions with randomized numbers and content can explore students' proficiency in course material. Using a fully interactive online textbook, Material and Energy Balances zyBook, success and attempts on homework questions are quantified. In past studies, students with an unlimited number of attempts completed a median of $94 \%$ correct over hundreds of questions. To provide students with more practice before exams, end-of-chapter problems were assigned. Students were only assigned a fraction of these summative, end-of-chapter problems. A single cohort of $\sim 100$ students generated data across 7 chapters before each of three midterm exams. Measuring if students correctly solved end-of-chapter problems beyond those required for a grade and if the extra practice helped their exam grades are central research themes. More specifically, several research questions will be explored: 1 . What fraction of students correctly solve problems beyond those earning a homework grade? 2. Does the fraction of students completed extra problems and the number of extra problems successfully completed change over the course of the semester? 3. Since previous research found that success on homework problems increases with each letter grade, does completing more end-of-chapter questions than required correlate with higher exam grades?
\end{abstract}

\section{Introduction}

Human interactions are being measured using digital tools from smartphones to watches, which creates big data. Analyzing this type of data can improve products, lifestyles, and education, which is the focus here. Specifically, higher education transitioned quickly to online platforms, which may have included interactive textbooks, during the global pandemic in 2020.

Interactive textbooks encompass both active learning and big data. First, active pedagogies are generally evidence-based methods showing student success. However, faculty may feel adopting a new teaching technology is a social change, which can lead to slower adoption [1,2]. Most previous work shows 20 to $50 \%$ of higher education students read traditional textbooks, but interactive textbooks have measured as high at 99\% median reading participation [3-8].

Accelerated by the shift in 2020 to remote instruction, students are expected to quickly master numerous digital platforms. Here, the focus is on online homework, which is common in math, chemistry, physics, and many introductory engineering courses. In general, online homework aligns with best practices in learning and several learning theories, including the use of visuals, immediate feedback, and scaffolding [9-13]. Research findings related to online homework are abundant in both science than engineering education [14-23]. Overall, online homework features multiple problem versions and attempts, which can benefit learning [24]. 
The first chemical engineering course centers on engineering problem solving based upon the conservation of mass and energy. The course is normally titled Mass and Energy Balances, and many contributions to the engineering education literature focus are available, e.g., [25-28]. The specific course of interest is secondary to the findings presented. Here, the analysis of end-ofchapter, summative problems will be explored.

\section{Materials and Methods}

A fully interactive textbook, Material and Energy Balances zyBook, has been used for a chemical engineering course at a public university for 5 years. The interactive content follows other textbooks for the course and is used within any HTML5 compliant web browser. Over 80 sections, 140 animations, and over 1300 clicks briefly quantify the interactivity. Over 600 online homework questions, or challenge activities, were available for the 2020 cohort. More specifically, the first seven chapters will be examined. Challenge activities are scored as correct or incorrect regardless of attempts, and challenge activities contributed $5 \%$ of a students' final course grade. A 15 -question forgiveness factor ( $\sim 3 \%$ of the assigned questions) was provided for the students' grades, however, fraction correct presented here includes all attempts without accounting for the forgiveness factor.

To provide students with more practice before each of the three midterm exams, end-of-chapter problems were assigned. Students earned a full grade for correctly answering only a percentage of the problems available. Students were given about one week to complete these problems before each exam. Midterm exams were taken in weeks 4, 9, and 13, with the final exam in week 15. End-of-chapter challenge activities are questions requiring multiple concepts from the chapter and likely many steps to solve. These summative problems can also encompass content from preceding chapters. In contrast, in-section challenge activities are present in most sections, consisting of 3 to 6 scaffolded, question levels. A student must answer an earlier question level before proceeding to the next question level. 266 in-section question levels were required to be completed before the third midterm exam and will be used as a comparison to end of chapter questions. Of total challenge activity questions, $19 \%$ encompass assigned end-of-chapter questions and the rest are in-section questions. All challenge activities have rolling numbers as well as changing content, thus, any question level can contain thousands of variations. Challenge activities have unlimited number of attempts without penalty. Examples of challenge activities were included in our previous papers [28, 29].

Table 1. Number of students and end-of-chapter challenge activity question levels required and available before each midterm exam.

\begin{tabular}{|l|c|c|c|c|}
\hline & Exam 1 & Exam 2 & Exam 3 & Final \\
\hline Students (\#) & 100 & 92 & 90 & 89 \\
\hline $\begin{array}{l}\text { Required } \\
\text { questions (\#) }\end{array}$ & 24 & 24 & 13 & - \\
\hline $\begin{array}{l}\text { Available } \\
\text { questions (\#) }\end{array}$ & 55 & 56 & 56 & - \\
\hline
\end{tabular}

The number of end-of-chapter questions varied for each exam with 20-40\% of available questions being required for homework points (Table 1). Thus, fraction correct may be presented as a percent of the required or available questions. A total of 104 students were initially enrolled, 
and 15 students did not complete the course. Between Exam 1 and 2, 8 students withdrew, which was the same time when the campus closed due to the COVID-19 pandemic. Analysis only encompasses students taking each midterm exam.

Some fraction correct data will be presented using box plots. Each box represents the middle $50 \%$ of data, including $1^{\text {st }}$ quartile, median, and $3^{\text {rd }}$ quartile. Using box plots, removes the effects of individual outliers that can skew average values. Average or mean values may also be included for added clarity of skewness. In correlating different data sets, hypothesis testing was conducted. Performing $t$-tests generated $p$ values with statistically significance being considered when $p<0.05$. Using $t$-tests is justifiable even with nonnormal distributions when $n>20$ [28].

\section{Results and Discussion}

Do students correctly solve problems not originally assigned?

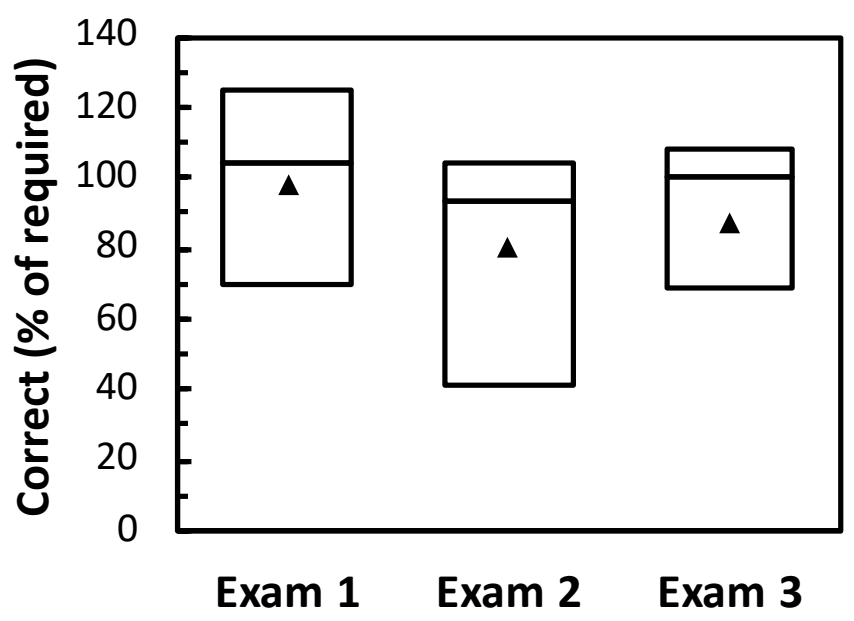

Figure 1. Fraction correct of end-of-chapter challenge activities required before each midterm exam. Triangles represent mean.

Table 2. $\mathrm{p}$ values for fraction correct across exams presented in Figure 1.

\begin{tabular}{|l|l|l|l|}
\hline Exam & 1 & 2 & 3 \\
\hline 1 & & 0.018 & 0.17 \\
\hline 2 & 0.018 & & 0.34 \\
\hline 3 & 0.17 & 0.34 & \\
\hline
\end{tabular}

Students correctly solved end-of-chapter challenge activities assigned before each of the three midterm exams (Figure 1). Median fraction correct was consistently high with median correct of 104, 100, and 94\% for Exams 1, 2, and 3, respectively. The $1^{\text {st }}$ quartile correct was highest for Exam 1 (125\%), and lowest for Exam 2 (104\%). Challenge activities before Exam 1 showed the highest overall correct, which may be for several reasons. First, the course was still fully inperson at this point and attendance/engagement was very high. Also, Chapter 1 is primarily review from previous courses and included unit conversions, significant figures, and other general skills. The widest variation in correct is for Exam 2, which occurred two weeks after 
Spring Break and coincided with the campus closure and shift to remote instruction. The dramatic improvement of the $3^{\text {rd }}$ quartile correct between Exams 2 and 3 may indicate students becoming more comfortable with remote learning as well as some students withdrawing from participating entirely in the course. Overall, some students, 25 to more than $50 \%$, correctly answered summative, end-of-chapter questions beyond the required amount before every exam.

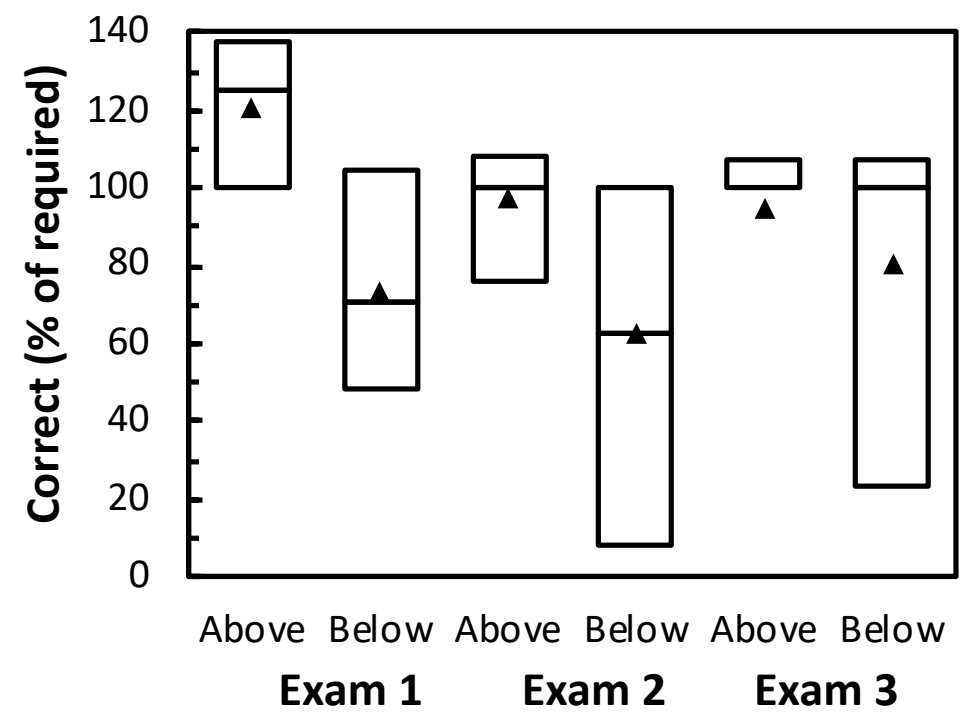

Figure 2. Fraction correct of end-of-chapter challenge activities required above and below median exam scores. Triangles represent mean. $\mathrm{P}$ values between above and below for each exam are $<0.001$.

Generally, students who correctly completed more end-of-chapter challenge activities performed better on exams. By separating each exam cohort into students who fell above and below the median exam score, statistically significant differences in fraction correct were found (Figure 2). For students scoring above the median exam score, the median fraction correct on end-of-chapter challenge activities were all at least $100 \%$, which confirms high engagement and preparation. For students below the exam median, median fraction correct varied, from 63 and $69 \%$ for the first two exams to $100 \%$ for Exam 3. Especially for Exams 2 and 3, the large deviations from median to $3^{\text {rd }}$ quartile correct are noted, which indicates that half of the students scoring below the median exam score could not correctly answer or did not attempt a significant number of the end-of-chapter challenge activities.

Table 3. Percent of students above or below $100 \%$ correct of required challenge activites.

\begin{tabular}{|l|c|c|c|}
\hline Correct (\%) & Exam 1 & Exam 2 & Exam 3 \\
\hline$>100$ & 52 & 29 & 34 \\
\hline$=100$ & 7 & 20 & 30 \\
\hline$<100$ & 34 & 46 & 19 \\
\hline 0 & 7 & 5 & 17 \\
\hline
\end{tabular}

Of the students taking each exam, high fractions of students correctly completed at or above the assigned number of end-of-chapter problems (Table 3). Exam 3 showed the largest percentage of 
students completing $100 \%$ or more of the required end-of-chapter challenge activities (64\%), followed by Exam 1 (59\%) and Exam 2 (49\%). Interestingly, more than four times the percent of students completed exactly 100\% for Exam 3 (30\%) than Exam 1 (7\%). This finding may be due to several factors, including screen fatigue from $100 \%$ remote learning or the length and difficulty of summative challenge activities for Exam 3. Questions involved both material and energy balances in all cases for Exam 3. Exam 3 also showed the largest percent of students not completing any challenge activities (17\%). The percent of students completing more than required decreased across exams, while the percent of students completed exactly $100 \%$ increased. As the semester progressed, students tended to have more of an all or nothing mindset on end-of-chapter problems.

How does completing more than asked correlate to exam grades?
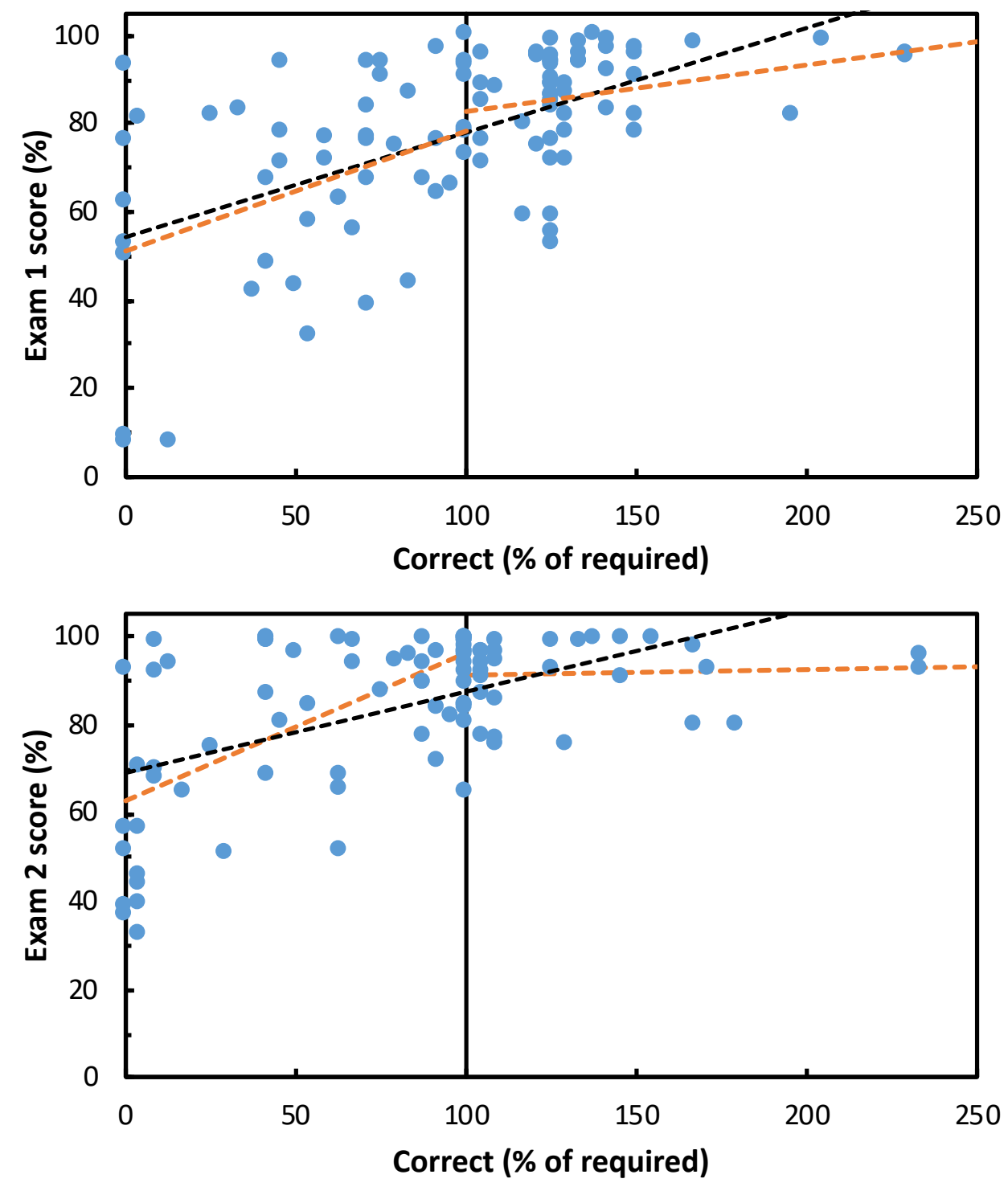


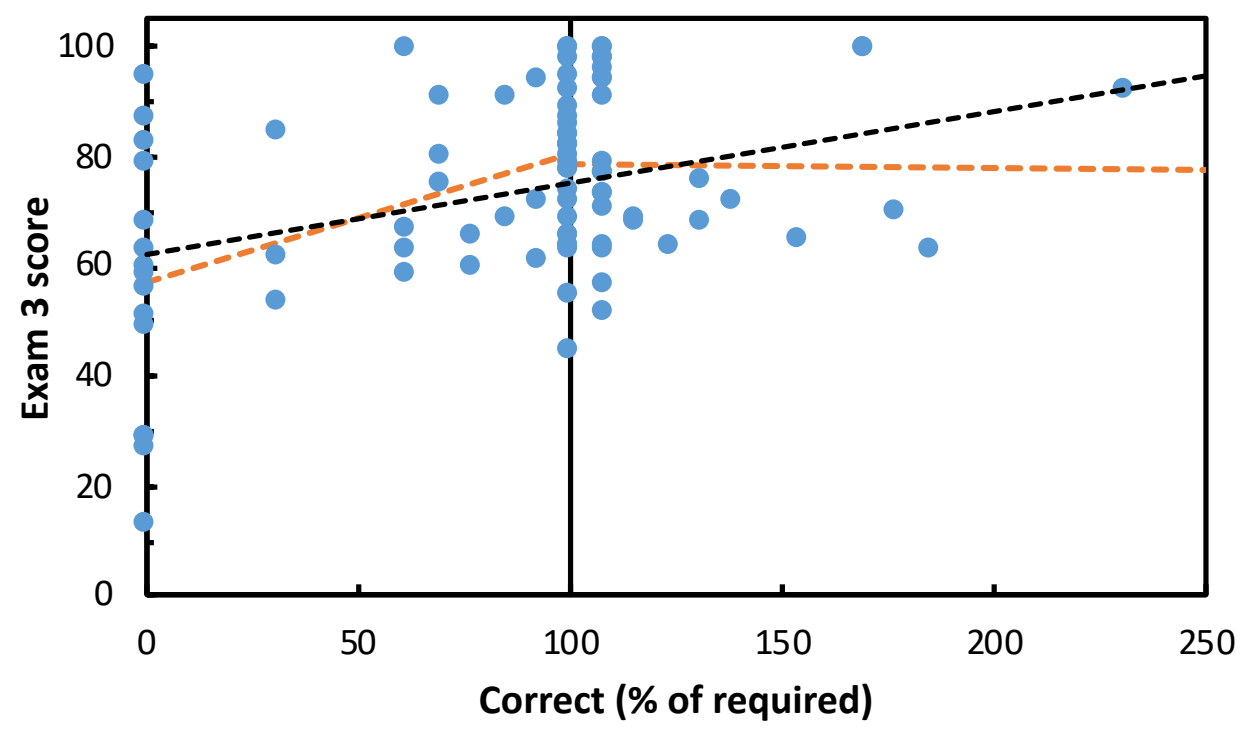

Figure 3. Exam score as a function of fraction end-of-chapter correct of challenge activities required.

Table 4. Slope and Pearson correlation coefficients for above and below $100 \%$ of required endof-chapter challenge activities correctly completed for each midterm exams.

\begin{tabular}{|l|c|c|c|c|c|c|}
\hline & \multicolumn{2}{|c|}{ Combined } & \multicolumn{2}{c|}{$<\mathbf{1 0 0 \%}$} & \multicolumn{2}{c|}{$\geq \mathbf{1 0 0 \%}$} \\
\cline { 2 - 7 } & $\mathbf{m}$ & $\mathbf{R}$ & $\mathbf{m}$ & $\mathbf{R}$ & $\mathbf{m}$ & $\mathbf{R}$ \\
\hline Exam 1 & 0.23 & 0.58 & 0.27 & 0.36 & 0.10 & 0.25 \\
\hline Exam 2 & 0.18 & 0.55 & 0.33 & 0.55 & 0.01 & 0.04 \\
\hline Exam 3 & 0.13 & 0.37 & 0.23 & 0.42 & -0.005 & 0.01 \\
\hline
\end{tabular}

Correctly completing more end-of-chapter challenge activities positively correlated with exam grades for all three midterm exams (Figure 3). Combining all students who took each exam, positive slopes were present as well as high Pearson coefficients (Table 4). Exam 1 resulted in the largest slope and largest Pearson coefficient, while Exam 3 resulted in both the lowest slope and Pearson coefficient. Overall, a positive correlation is present until $100 \%$ correct where then the trend levels off. The more practice the student has, the better expected to perform on the exam.

Below 100\% correct for end-of-chapter challenge activities, Exam 2 resulted in the largest slope and largest Pearson coefficient, while Exam 1 had the lowest Pearson coefficient and Exam 3 had the lowest slope. High exam scores were recorded for $<5$ students who did not complete most, or all assigned questions. These students are considered outliers in terms of end-of-chapter problem completion. Greater than or equal to $100 \%$ resulted in decreasing slopes and Pearson coefficients as exams progressed. Exam 3 resulted in a slightly negative slope, which may be due to an outlier who correctly completed $277 \%$ of assigned challenge activities but scored $70 \%$ on the exam. A low Pearson coefficient signifies a poor linear correlation, which for students completing more than required is shown to have flat trend lines. Those who overachieve on challenge activities are more likely to receive higher exam grades which corresponds to an A or B. The y-intercepts for greater than $100 \%$ for all exams is in the B range and since the trend lines 
closely represent horizontal fits, students who overachieve, correlate to high exam scores. Those who overachieve on challenge activities are more likely to receive higher exam grades, which corresponds to an A or B. The y-intercepts for greater than $100 \%$ of required for all exams is in the B range. Since the trend lines closely represent horizontal fits, students who overachieve, correlate with high exam scores.

Does correctly completing more problems make a difference?
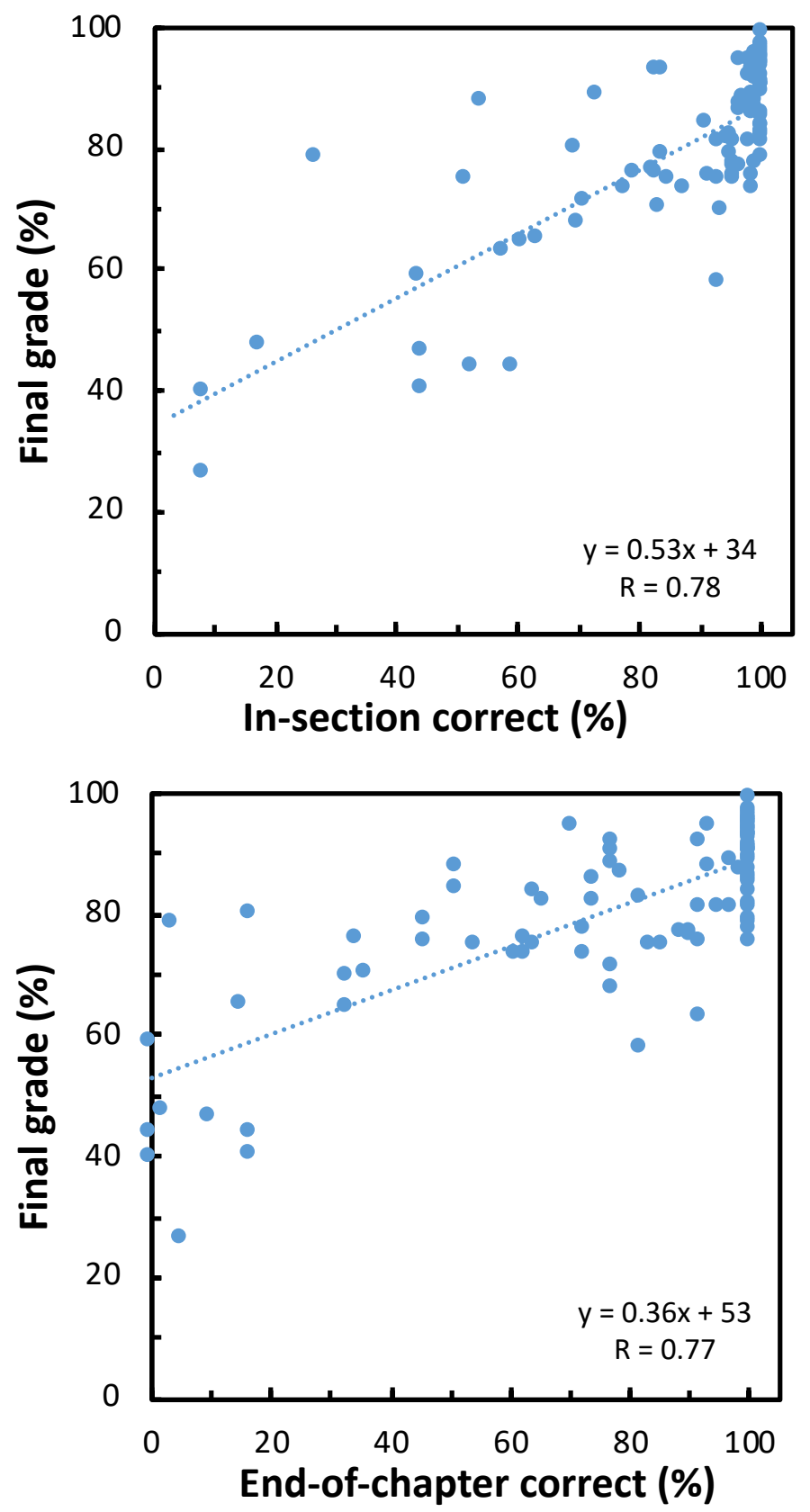

Figure 4. Top. Final grade as a function of fraction correct of in-section challenge activities. Bottom. Fraction correct of end-of-chapter challenge activities. 
When comparing final course grades to fraction correct of both in-section and end-of-chapter challenge activities, similar, positive correlations were found (Figure 1). In-section correct was aggregated from fraction correct of challenge activities assigned across Chapters 1 through 7. The maximum score is $100 \%$. End-of-chapter correct was aggregated from fraction correct of challenge activities assigned before each exam, but here, is capped at $100 \%$ for a direct comparison with in-section correct. Thus, completing over $100 \%$ of the end-of-chapter challenge activities, as presented earlier, is re-adjusted to $100 \%$ in Figure 4Figure 1. Final grade as a function of in-section correct resulted in a positive linear correlation with slope of 0.53 and Pearson coefficient of 0.78 . Furthermore, final grade as a function of end-of-chapter correct resulted in a positive linear correlation with slope of 0.36 and Pearson coefficient of 0.77 . Insection correct data qualitatively shows less variability than end-of-chapter correct. Specifically, four students fall below $20 \%$ in section correct, while 15 students fall below $40 \%$ end-of-chapter correct. For both formative (in-section) and summative (end-of-chapter) challenge activities, the more correctly solved challenge activities correlated with higher final grades.

\section{Conclusion}

Student usage and course success related to auto-graded, end-of-chapter problems was explored. Providing students with summative practice problems before each midterm exam included a requirement of completing only a percentage of the available problems to receive a full homework grade. Many students correctly solved auto-graded problems that did not directly improve their grades. High engagement and preparation were confirmed by students scoring above the median exam score with median fraction correct on end-of-chapter challenge activities at least $100 \%$ for all three exams. Exam 1 showed the highest fraction correct and largest percentage of students correctly completing more than required, which may be related to having in-person instruction or some content that was covered in previous courses.

Correctly completing more end-of-chapter problems positively correlated with all three midterm exam grades, which were quantified by high Pearson coefficients. The positive linear correlation was larger for students completing less than $100 \%$ of the required problems. Since previous research found that success on homework problems increases with letter grade, when comparing final course grades to fraction correct of both in-section and end-of-chapter challenge activities, strong positive linear correlations were present. Since problem solving skills exhibited on autograded problems transferred to new problems on exams, these findings add to the literature related to focused practice.

\section{Acknowledgments}

The authors thank contributions from Alex Edgcomb and numerous teaching assistants. This work was completed within the framework of University of Toledo IRB protocol 201808.

\section{Disclaimer}

One of the authors may receive royalties from sales of the zyBook detailed in this paper. 


\section{References}

[1] National Academy of Engineering, Educating the engineer of 2020: Adapting engineering education in the new century. National Academies Press, 2005.

[2] C. C. Martin, W. C. Newstetter, and J. M. Le Doux, "Inclusion requires a comprehensive understanding of justice," Journal of Engineering Education, vol. 108, no. 4, pp. 453-458, 2019, doi: https://doi.org/10.1002/jee.20296.

[3] X. Bai, A. Ola, E. Eyob, S. Reese, S. Akkaladevi, and D. Downing, "Another look at textbook usage by college students," Issues in Information Systems, vol. 20, no. 4, pp. 35-44, 2019.

[4] C. M. Burchfield and T. Sappington, "Compliance with required reading assignments," (in English), Teaching of Psychology, vol. 27, no. 1, pp. 58-60, Win 2000, doi: https://psycnet.apa.org/record/2000-07173-017.

[5] M. W. Liberatore, K. E. Chapman, and K. M. Roach, "Significant reading participation across multiple cohorts before and after the due date when using an interactive textbook," Computer Applications in Engineering Education, vol. 28, no. 2, pp. 444-453, 2020, doi: https://doi.org/10.1002/cae.22210.

[6] T. Culver and S. Hutchens, "Toss the Text? An Investigation of Student and Faculty Perspectives on Textbook Reading," Journal of College Reading and Learning, pp. 1-14, 2020, doi: 10.1080/10790195.2020.1734884.

[7] M. W. Liberatore, "High textbook reading rates when using an interactive textbook for a Material and Energy Balances course," Chemical Engineering Education, vol. 51, no. 3, pp. 109-118, 2017, doi: https://journals.flvc.org/cee/article/view/104416.

[8] M. W. Liberatore, K. Chapman, and M. Davidson, "Quantifying success and attempts on autograded homework when using an interactive textbook," in ASEE Annual Conference, 2020, pp. 1-12, doi: https://peer.asee.org/35116.

[9] S. Mintz. "Can Technology Make Grading Fairer and More Efficient?" https://www.insidehighered.com/blogs/higher-ed-gamma/can-technology-make-gradingfairer-and-more-efficient (accessed 11, 2020).

[10]R. M. Felder and R. Brent, Teaching and Learning STEM: A Practical Guide. San Francisco, CA: Jossey-Bass, 2016.

[11]L. Deslauriers, L. S. McCarty, K. Miller, K. Callaghan, and G. Kestin, "Measuring actual learning versus feeling of learning in response to being actively engaged in the classroom," Proceedings of the National Academy of Science, vol. 116, no. 39, pp. 19251-19257, Sep 24 2019, doi: https://doi.org/10.1073/pnas.1821936116.

[12]J. M. Lang, Small Teaching: Everyday Lessons from the Science of Learning. John Wiley \& Sons, 2016.

[13]J. D. Bransford, A. L. Brown, and R. R. Cocking, Eds. How People Learn: Brain, Mind, Experience, and School: Expanded Edition. National Academies Press, 2000.

[14]M. Richards-Babb, R. Curtis, Z. Georgieva, and J. H. Penn, "Student Perceptions of Online Homework Use for Formative Assessment of Learning in Organic Chemistry," J Chem Educ, vol. 92, no. 11, pp. 1813-1819, Nov 10 2015, doi: 10.1021/acs.jchemed.5b00294.

[15]G. Kortemeyer, E. Kashy, W. Benenson, and W. Bauer, "Experiences using the open-source learning content management and assessment system LON-CAPA in introductory physics courses," American Journal of Physics, vol. 76, no. 4, p. 438, 2008, doi: https://doi.org/10.1119/1.2835046. 
[16]E. McGroarty et al., "Supplementing introductory biology with on-line curriculum*," Biochemistry and Molecular Biology Education, vol. 32, no. 1, pp. 20-6, Jan 2004, doi: https://doi.org/10.1002/bmb.2004.494032010312.

[17]L. Nabulsi, A. Nguyen, and O. Odeleye, "A Comparison of the Effects of Two Different Online Homework Systems on Levels of Knowledge Retention in General Chemistry Students," Journal of Science Education and Technology, 2020, doi: 10.1007/s10956-02009872-2.

[18]L. L. Parker and G. M. Loudon, "Case Study Using Online Homework in Undergraduate Organic Chemistry: Results and Student Attitudes," Journal of Chemical Education, vol. 90, no. 1, pp. 37-44, 2012, doi: 10.1021/ed300270t.

[19]K. D. Revell, "A Comparison of the Usage of Tablet PC, Lecture Capture, and Online Homework in an Introductory Chemistry Course," Journal of Chemical Education, vol. 91, no. 1, pp. 48-51, 2013, doi: 10.1021/ed400372x.

[20]A. L. Elias, D. G. Elliott, and J. A. W. Elliott, "Student perceptions and instructor experiences in implementing an online homework system in a large second-year engineering course," Education for Chemical Engineers, vol. 21, pp. 40-49, 2017, doi: 10.1016/j.ece.2017.07.005.

[21]J. S. Lee and J. Verrett, "Webwork as an open online homework system in material and energy balances," in Canadian Engineering Education Association (CEEA18) Conference, 2018.

[22]P. S. Steif and A. Dollar, "Study of usage patterns and learning gains in a web-based interactive static course," (in English), Journal of Engineering Education, vol. 98, no. 4, pp. 321-333, Oct 2009, doi: https://doi.org/10.1002/j.2168-9830.2009.tb01030.x.

[23] M. W. Liberatore, "Improved student achievement using personalized online homework for a course in material and energy balances," Chemical Engineering Education, vol. 45, no. 3, pp. 184-190, 2011, doi: https://journals.flvc.org/cee/article/view/122149.

[24]J. Medina, Brain Rules 12 Principles for Surviving and Thriving at Work, Home, and School. Pear Press, 2008.

[25]D. L. Silverstein, L. G. Bullard, and M. A. Vigeant, "How we teach: Material and energy balances," in ASEE Annual Meeting, San Antonio, TX, 2012, p. 3583, doi: https://peer.asee.org/21460.

[26]M. W. Liberatore, "Active learning and just-in-time teaching in a material and energy balances course," Chemical Engineering Education, vol. 47, no. 3, pp. 154-160, 2013, doi: https://journals.flvc.org/cee/article/view/114520.

[27]D. A. Amos, C. M. Pittard, and K. E. Snyder, "Active learning and student performance in a Material and Energy Balance Course," Chemical Engineering Education, vol. 52, no. 4, pp. 277-286, 2018.

[28]K. E. Chapman, M. E. Davidson, and M. W. Liberatore, "Student success and attempts on auto-graded homework across multiple cohorts in material and energy balances," Chemical Engineering Education, vol. 55, no. 1, pp. 43-50, 2021, doi: https://doi.org/10.18260/2-1370.660-123169.

[29]M. W. Liberatore, "Reading analytics and student performance when using an interactive textbook for a material and energy balances course," in ASEE Annual Conference \& Exposition, Columbus, OH, 2017, pp. 1-13, doi: https://peer.asee.org/28780. 